\title{
COVID-19 and Emergency e-Learning in Political Science and International Relations
}

\author{
INTRODUCTION: COVID-19 AND EMERGENCY E-LEARNING IN \\ POLITICAL SCIENCE AND INTERNATIONAL RELATIONS
}

Eric D. Loepp, University of Wisconsin-Whitewater

\section{DOI:10.1017/S1049096520001511}

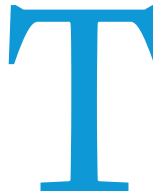

he COVID-19 pandemic accelerated an integration of online learning into higher education that was well underway in political science before the virus struck. However, the swiftness of its arrival and the severity of its disruption prompted an abrupt and difficult conversion to digital education for which few instructors were adequately prepared. Indeed, the challenges we experienced in spring 2020 were not strictly a function of remote educationthey were the result of emergency e-learning. Although academic programming in fall 2020 and beyond will benefit from extra time to prepare, new challenges and emergencies stemming from the pandemic's many uncertainties likely will constrain higher education for the foreseeable future. To ease these transitions, this spotlight offers insights for political science educators from colleagues across the discipline.

Some of the most helpful guidance also comes from students. I administered a multi-wave survey to students to capture their views on e-learning in spring 2020. ${ }^{1}$ The first survey was distributed during the week of March 29, immediately on resumption of classes after spring break; the second was completed during the week of May 10, at the end of the term. More than 100 students completed each survey, and their comments are instructive. Figure 1 illustrates an average ranking of six important items related to online learning, in which higher averages indicate a greater priority. ${ }^{2}$ The data demonstrate that students this past spring were principally concerned about learning material and academic performance.

At the end of the term, students reflected on their emergency e-learning experience and again rank-ordered several items. This time, they indicated what made for a successful remote-learning experience. Figure 2 summarizes the average ranking of these four factors. By far, the feature most associated with a positive online experience was a good professor. Although a quality instructor certainly can condition the value of other features of an online course, the data underscore that it was the person-not the material or the technology-that made courses successful. When asked to elaborate, students indicated that their best professors communicated frequently, were easy to contact/access, maintained a clear and navigable learning-management system, and embraced flexibility as a core pedagogical tenet.

I also collected written feedback on how we can best meet student needs moving forward. Three main themes emerged, as follows:
- Compassion: Many students referenced the challenging learning environment posed by the remote-learning transition. Some concerns were logistical: new work schedules or obligations made it impossible for them to "attend" class at the regularly scheduled period. Others were constrained by technical problems such as a poor Internet connection. Still others faced distractions at home that made it difficult to create a space conducive to learning. Consequently, students frequently expressed appreciation for faculty understanding their limitations and anxiety, and for adjusting course expectations accordingly. Flexibility is a critical part of successful emergency e-learning.

- Communication: Professors earned high praise for committing to regular contact with students-both proactively and reactively. Students appreciated when instructors reached out to provide updates, course reminders, or even simply to say hello and ask how they were doing. Students also greatly value responsiveness. One individual noted that "if something was confusing, [students] were not able to raise our hand" as in a classroom. Therefore, responding quickly to inquiries is especially critical in an emergency e-learning setting.

- Navigation: One of the most frequent references in student feedback was to our learning management system (i.e., Canvas). Approximately one of three students mentioned the platform in their responses. Students praised well-designed Canvas pages and lamented those that were not. One student summarized well the collective view when describing their top professors this past spring: "They were [the best] at remote teaching/instruction because everything on Canvas was organized very clearly and there was never anything that was due that I did not know about a very long time in advance. There were no surprises[,] which was also very helpful for my stress levels."

Political science instructors should take comfort in knowing that these types of comments are consistent with much of the preCOVID-19 literature on pedagogical practice. Indeed, the current research on distance education has long affirmed the value of faculty presence and building relationships. For instance, faculty who take time to build rapport with students can boost motivation (e.g., Dickinson 2017) and improve academic performance (e.g., Glazier 2016). Similarly, taking time to introduce students to online course technologies and navigation also promotes success (e.g., Taylor, Dunn, and Winn 2015). ${ }^{3}$

Nevertheless, the immediate future poses unique challenges for our field. It is safe to assume that many of students' academic priorities and concerns in fall 2020 and beyond are similar to those expressed last spring, and that some general best practices 
will be broadly applicable. However, it is equally important to recognize the vast array of contexts in which political science educators operate. After all, universities differ considerably, from
Disseminating these experiences enables us to learn from one another-to consider how circumstances our colleagues have faced may inform our own pedagogical strategies in the future. This

\section{This spotlight convenes scholars from around the world to share their experiences and to recommend best practices following the tumultuous spring 2020 term.}

the populations they serve to the severity of health threats in their locale. Consequently, although the pandemic disruption was universal, the transition to emergency e-learning took many forms, and instructors experienced and endured a wide variety of contingencies. spotlight convenes scholars from around the world to share their experiences and to recommend best practices following the tumultuous spring 2020 term. Topics range from overcoming administrative challenges to promoting online engagement. Our objective is to advance a dialogue within the political science community about

\section{Figure 1}

Student Priorities Before Online Transition

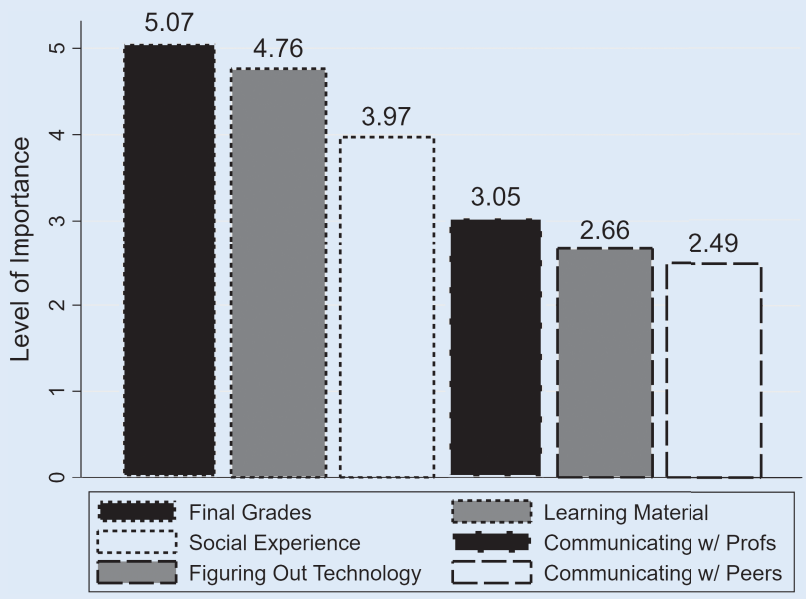

\section{Figure 2}

\section{Most Important Features of a Successful Remote-Learning Experience}

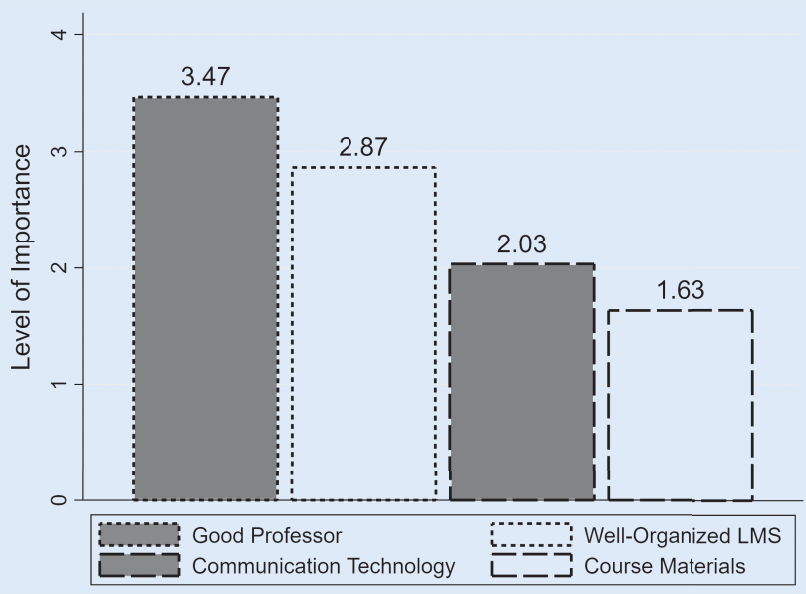


how we can best proceed collectively during the pandemic and its aftermath, especially concerning the unique challenges we face in our field.

Of course, no single discussion can speak to every concern or challenge that educators will face in a discipline as diverse as ours. Additional avenues of inquiry will emerge as classes resume; indeed, we close this spotlight with recommendations for additional scholarship on this topic. Emergency e-learning is distinct in many ways from traditional online coursework; in this way, it is new for all of us, as well. However, this assembly of scholars thoughtfully reflects on many of the key challenges that instructors of political science and international relations face moving forward, and their commentary can inform important discussions within departments and across universities. It is our sincerest hope that this spotlight contributes to a wider conversation about how we can best serve students throughout this pandemic and in the years to come.

\section{NOTES}

1. Survey participants were enrolled in one of four political science courses that taught in spring 2020: American Minority Politics (two sections), Picking President, and Political Science Research Methods. There were approximately 140 students across these four sections; 111 students completed the first survey (79.29\% response rate) and 103 students completed the second survey $(73.6 \%$ response rate). Slightly more than half of the sample was female (53\%) and slightly less than $86 \%$ of students were white. The average respondent was 20.6 years old, and approximately $81 \%$ had previously taken at least one online course.

2. The six statements were presented in random order; respondents arranged them such that the issue they were most concerned about was at the top and the issue they were least concerned about was at the bottom. The full text for the six items is as follows: my final grade in the course; my learning of the course material; figuring out remote learning technology; missing my social experience on campus; being able to communicate with my professor; and being able to communicate with my peers.

3. For an extended discussion of literature related to teaching political science online, see Loepp 2020.

\section{REFERENCES}

Dickinson, Amber. 2017. "Communicating with the Online Student: The Impact of E-Mail Tone on Student Performance and Teacher Evaluations." Journal of Educators Online 14 (2). Available at https://eric.ed.gov/?id=EJ1150571.

Glazier, Rebecca. 2016. "Building Rapport to Improve Retention and Success in Online Classes." Journal of Political Science Education 12 (4): 437-56.

Loepp, Eric. 2020. “Teaching Political Science Online.” Available at https:// seagull.wwnorton.com/teachingpoliscionlineguide.

Taylor, Jean, Margie Dunn, and Sandra Winn. 2015. "Innovative Orientation Leads to Improved Success in Online Courses." Online Learning 19 (4). Available at https:/ eric.ed.gov/?id=EJ1079576.

\section{WHEN TEACHING IS IMPOSSIBLE: A PANDEMIC PEDAGOGY OF CARE}

\section{Oumar Ba, Morehouse College}

\section{DOI:10.1017/S10490965200015oX}

I teach at Morehouse College, an all-male, historically Black institution. Historically Black Colleges and Universities (HBCUs) were established to provide opportunities for access to higher education for African Americans when legal segregation characterized the United States. Currently, there are 101 accredited HBCUs, both public and private. Located predominantly in the southeastern United States, HBCUs enroll 300,000 students, $80 \%$ of whom are African American and $70 \%$ of whom are from low-income families. ${ }^{1}$ Although there is variation among these institutions, to a large extent they nevertheless share many features. They tend to be burdened by a lack of financial resources, even before the challenges resulting from the COVID-19 pandemic. For instance, in 2018 , only $1.4 \%$ of total major gifts (i.e., more than 1 million dollars) to US colleges and universities went to HBCUs (Price 2020). In such a climate of scarcity, how do we adjust the classroom in response to the disruption caused by the pandemic in the middle of the 2020 spring semester?

The mission of Morehouse College is "to develop men with disciplined minds who will lead lives of leadership and service." The College also "assumes special responsibility for teaching the history and culture of Black people."2 Brotherhood, belonging, and community are essential in the making of the "Morehouse Man." Therefore, the disruption that the pandemic caused, and the closure of the campus, presented a challenge to maintain that educational and social community for the students.

This article focuses on my Introduction to IR course. The majority of the 40 students in the class were freshmen and sophomores pursuing a degree in political science or international studies. A few students from other departments across campus also take the course to fulfill their general education requirement. In mid-March 2020, with only one week to prepare, we were forced to switch to remote delivery of all courses for the second half of the semester, and all students were required to evacuate their campus housing. I adopted what has been referred to as "pandemic pedagogy," with a range of e-learning strategies dictated by the emergency situation. A pandemic pedagogy, as defined by Smith and Hornsby $(2020,1)$, refers to "the approaches we employ in our learning environments to teach and foster learning in the context of a serious health crisis and the spread of a new disease." As the authors explain, this pandemic moment and its meanings and responses to them are infused with power, pedagogy, and politics.

Instruction during the pandemic occurs in moments of profound disruption in the lives of the students-and instructors-and anxiety associated with trying to establish a new normal under extraordinarily abnormal circumstances. Moreover, for an institution like Morehouse, an adaptive pedagogy must be mindful of the technological gap and digital divide that many students experience. For instance, the College had to raise funds to provide computers, tablets, and Internet access for some students. ${ }^{3}$ Emergency housing also had to be provided for those who could not simply "go home." During the pandemic, some students also notified me that they had family members who were either sick or had died from COVID-19. This calls for a pedagogy of care, not because our students are incapable of facing and surmounting challenges but rather because they are already in a disadvantaged position, which compounds the effects of the pandemic. A pedagogy of care entails a commitment to ensure that students will have the support they need to submit all assignments and complete the course.

The making of a "Morehouse Man" rests on the building and sustaining of a community of brotherhood and learning. When the course moved to an online format, it therefore was essential to maintain such a community of learning and intellectual support, especially for freshmen and sophomores in a course designed to introduce them to the IR subfield. This process was accomplished through a hybrid model of asynchronous lectures with synchronous class discussions, which ensured the continued social presence of students. I prerecorded the video lectures and posted them on the course website the day before class meetings. Therefore, the synchronous class sessions-twice a week-over Zoom would not 